\title{
Capital femoral physeal dysplasia in cats submited to ostectomy of the femoral head and neck
}

\author{
Tryssia Scalon Magalhães Moi ${ }^{*}$ (i) Marco Aurélio Molina Pires ${ }^{2}$ (i) Kelly Cristiane Ito Yamauchi ${ }^{2}$ \\ Luís Gustavo Gosuen Gonçalves Dias ${ }^{1}$ (D) Bruno Watanabe Minto ${ }^{1}$ (i)
}

${ }^{1}$ Programa de Pós-graduação em Cirúrgica Veterinária, Universidade Estadual Paulista “Julio Mesquita Filho” (UNESP), 14883-296, Jaboticabal, SP, Brasil. E-mail: tixa moi@hotmail.com. *Corresponding author.

${ }^{2}$ Departamento de Cirúrgia Veterinária, Universidade de Cuiabá (UNIC), Cuiabá, MT, Brasil.

ABSTRACT: This report described pathological fracture of the femoral head (physeal dysplasia) in four male cats (three mixed breed and one Bengal), with an average age of 16 months, treated by an ostectomy of the femoral head and neck. Three cats were neutered and one entire. All presented with mild intermittent lameness in the pelvic limbs. Displacement of the femoral epiphysis and resorption of the femoral neck were present and excision of the femoral head and remaining neck was performed in all cases. Hstological examination showed mild foci of compaction and trabecular fibrosis with deposition of fibrous connective tissue, permeated by granulation tissues, consistent with the original diagosis. Limb function improved in all patients from 2 to 4 weeks postoperatively. Diagnosis of physeal dysplasia is challenging and treatment is different from acute traumatic fractures. Femoral head and neck excision was considered a good alternative in these patients.

Key words: colocefalectomy, dysplasia, epiphysiolysis, ostectomy, slipped capital femoral epiphysis.

Displasia femoral capital em felinos submetidos a ostectomia da cabeça e colo femoral

RESUMO: Este trabalho descreve a fratura patológica da cabeça do femur (displasia fiseal) em quatro machos (três raças mistas e um Bengal), com idade média de 16 meses, que foram tratados com ostectomia da cabeça e colo femorais. Três gatos eram castrados e um inteiro. Todos apresentaram leve claudicação intermitente nos membros pélvicos. O deslocamento da epifise femoral e a reabsorção do colo femoral estavam presentes, a excisão da cabeça e colo femoral foi realizada em todos os casos. O exame histológico mostrou focos de compacteção e fibrose trabecular com deposição de tecido conjuntivo fibroso, permeado por tecidos de granulação, consistentes com o suposto diagnóstico. A função dos membros melhorou em todos os paciente entre dois a quatro semanas pós-operatório. O diagnóstico da displasia fiseal pe desafiador e o tratamento é diferente das fraturas traumáticas agudas. A excisão de cabeça e colo femoral é considerada uma boa alternativa nesses pacientes.

Palavras-chave: colocefalectomia, displasia, epifise femoral de capital escorregadia, epitisiólise, ostectomia.

Capital femoral physeal dysplasia also referred to as slipped capital femoral epiphysis (SCFE), feline capital physeal dysplasia syndrome and spontaneous capital femoral physeal fracture is the result of weakening of the proximal epiphyseal cartilage of the femur. This results in progressive displacement, either unilateral or bilateral, of the superior femoral epiphysis of the proximal metaphysis of the femur, through the growth plate, with no history of significant trauma (BORAK et al., 2016).

In normal cats the physis is fully closed between the 7th and 10th month of age,; however, there are reports of cats affected with SCFE up to 24 months after the expected time of physeal closure (HARASEN, 2004).
Some authors considered this to be a common disease in cats (FISCHER et al, 2004) whilst others report it to be uncommon (RAHAL et al., 2015). Some breeds such as the short-haired Siamese, Siamese Cross, British Blue and Birman are predisposed to its development, or are overrepresented. SCFE has a multifactorial etiology, including genetic factors, accelerated growth, obesity, endocrine imbalances, sex and early castration (GEMMILL et al., 2012; SCHWART., 2013).

Treatment is usually based on femoral head and neck osteotomy (FHNO) or total hip arthroplasty (BORAK et al., 2016); however, there are reports of conservative care or even joint preservative therapy by means of surgical reduction and stabilization with 
multiple pins or K wires (FISCHER et al., 2004; GEMMILL et al., 2012).

This study reported a series of four cases of SCFE in cats without history of trauma, that were histopathologically confirmed. All patients were treated usins the FHNO technique and presented good postoperative results. SPCE is underdiagnosticated and frequently uncorfirmed through histopatogy examination.

Patient number 1 (P1) was a one-year-old, mixed breed, male, (neutered at 7 months of age) and raised in a residential home. The cat was refered to the Veterinary Teaching Hospital (Faculty of Veterinary Medicine of University of Cuiabá) with pelvic limb lameness of 3 days duration, bilateral pain and crepitus in the hips, with no history of outdoor access, or potential trauma. The other three patients (P2, P3 and P4) were refered to the Veterinary Teaching Hospital of the Faculty of Agricultural and Veterinary Sciences (São Paulo State University - Unesp / campus de Jaboticabal). P2 and P3 were male, mixed breed cats; while P4 was a male Bengal. P2 had been neutered at 7 months and P4 at 4 months. P3 was intact. All cats had free access to outdoors.

On orthopedic and neurological examination all reflexes were present and normal, with signs of pain / discomfort and crepitus on the Ortolani test. The animals were sedated with Tiletamine in combination with Zolazepan $5 \mathrm{mg} /$ $\mathrm{kg}$, intramuscularly (IM) (Zoletil ${ }^{\circledR} 50$, Tiletamine and Zolazepan, Virbac, France). Craniocaudal and mediolateral pelvic radiographs were taken in hip extension. Bilateral physeal fractures of the femoral head were present in P1 and unilateral fractures in the other cases (P2, P3 and P4).

P1 had a Salter Harris type I fracture in the physis of the right femoral head and a type II fracture in the head and part of the femoral neck. P2 had osseous discontinuity in the left femoral neck, with dorsal displacement of the femur, type I fracture. P3 had growth plates compatible with age, and a fracture of the right femoral neck, with anatomical conformational alterations more evident in the ventrodorsal projection, mild reduction in definition of the trabecular bone in the right ischium visible on the ventrodorsal projection, and was classified as Salter Harris type I fracture. P4 had a type I fracture. All cats had muscle atrophy in affected limbs on radiographic images (Figure 1). Laboratory tests were performed to assess liver, kidney and hematological functions, and no cat showed any significant changes. Head and neck osteotomies were performed for all affected femurs. Immediately following surgery radiography was performed to assess femoral positioning (Figure 2). Postoperative analgesia, antiinflammatory drugs and antibiosis was given. All animals had mild lameness post-operatively, that persisted for an average of 13 days.

P1 showed improvement in function in both limbs in the immediate postoperative (PO) period, with mild bilateral lameness. Re-evaluation was perfomed 7 days post-operatively at which time, according to the owner, lameness had resolved and normal limb function had returned. No pain was elicited on examination and there was significant

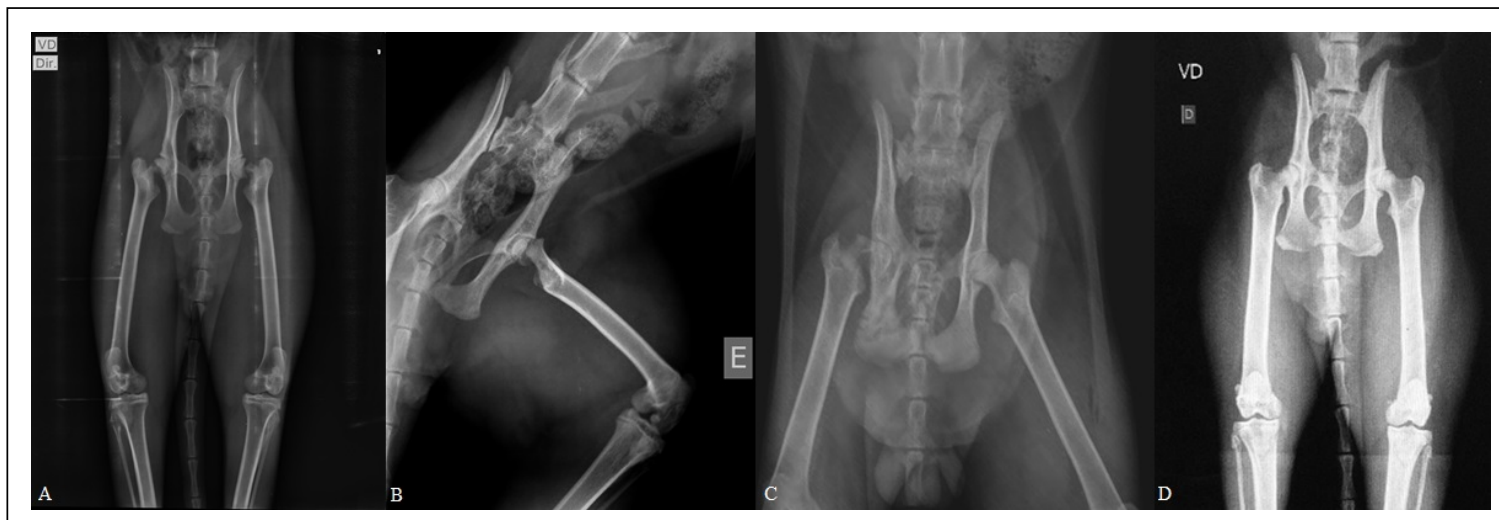

Figure 1 - Ventrodorsal projections of the coxofemoral region. A) P1 with bilateral physeal fracture of the femoral head, classified as Salter Harris fracture type I and type II of the right and left sides, respectively. B) P2 showing a type I physeal fracture in the left femoral head. C) P3 with a type I right femoral head fracture. D) Type I physeal fracture in the right femoral head of P4. 


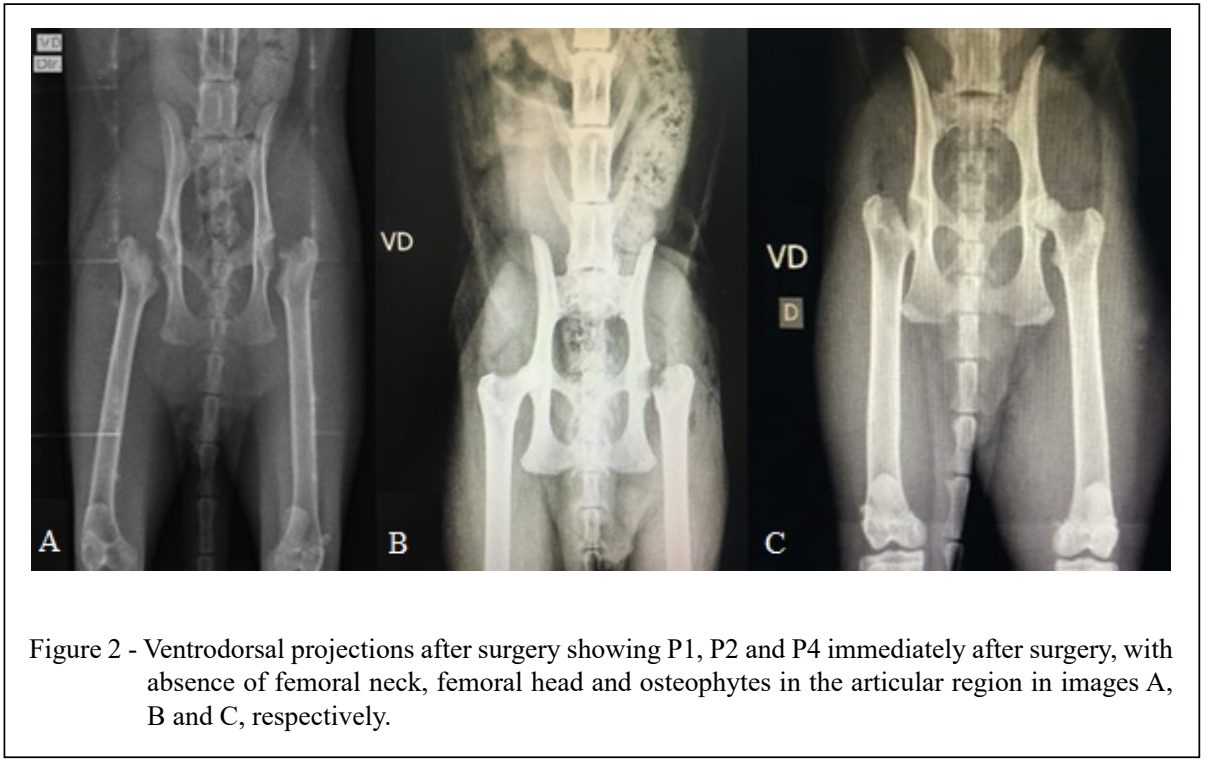

clinical improvement. P2, P3 and P4 had mild lameness in the affected limbs immediately postoperatively. P2 was not rested, but on the 12th PO day was walking normally and climbing up to windows, according to videos provided by the owner. On orthopedic examination P2 had no pain on hip palpation at this time. P3 returned for suture removal on the 13th day, when mild lameness in the affected limb was still present. However, on 20th PO day the animal was reevaluated and was walking normally and had returned to normal activities at home. P4 returned on 10th PO day to for suture removal and was showing clinical improvement, full weight-bearing on the affected limb, and no joint pain during palpation. After reexamination for radiographic monitoring to exclude contralateral physeal fracture, it was reported that on the 13th PO day the animal had returned to its routine of climbing onto beds and jumping without showing signs of pain. Physiotherapy was recommended in the PO period to all patients, but none of the owners followed this advic. All cats were followed up to rule out contralateral fractures until 45 days $\mathrm{PO}$, none of P2, P3 and P4 developed contralateral fracture.

The histopathologic examination of samples from P1 was performed at the Department of Veterinary Pathology of Veterinary Hospital, while the histopathologic examinations of P2, P3 and P4 were sent to VETPAT, a pathology laboratory in Campinas - SP.

On histopathologic examination samples from P1 showed multifocal areas of necrosis and hemorrhage associated with moderate neovasculation and deposition of fibrous connective tissue and moderately thickened bone trabeculae, with granulation tissue. Histopathologic examination of P2, P3 and P4 samples showed partially preserved bone architecture, highlighting mild foci of trabecular compaction, permeated by reactive fibrovascular tissue and mild bone resorption in the femoral head. Moderate infiltration of lymphocytes and plasma cells was observed in the areas of trabecular fibrosis, the chondroid layer was fragmented and irregular with foci of degeneration, permeated by mild granulation tissue. None of the cats had any characteristics of malignancy in the samples.

SCFE is described mainly in young animals between 4.5 and 24 months old (HARASEN, 2004), as was the case for three of four cats in this report. P4; however, showed signs at 30 months old, which is later than previous literature reports. Sex, age, weight and breed of the cats in this report are shown in table 1.

Various factors, including genetics, obesity, endocrine imbalances, neutering, and sex, are believed to play role in the development of the disease. SPFE is mainly reported in European Shorthairs, Siamese and Maine Coons (DEGÓRKA et al., 2017).

Being a neutrered male is a risk factor for late physeal closure, as sex hormones are responsible for growth plate closure (BORAK et al., 2016). However, not all cases can be related to

Ciência Rural, v.51, n.7, 2021. 
Table 1 - Data from cats in the study.

\begin{tabular}{lcccc}
\hline FELINE & 1 & 2 & 3 & 4 \\
\hline Sex & Male & Male & Male & Mhole male \\
Neutered (months) & 7 & 7 & 3.0 & 7 \\
Weight (kg) & 3.2 & 4.25 & 5 & Right \\
Onset of clinical signs (months) & 12 & 20 & 20 & Right \\
Affected member & Right/left & Left & 13 \\
Return of function the member (days) & 7 & & 20 \\
\hline
\end{tabular}

early neutering because there are reports of physeal dysplasia in intact male and female cats (CRAIG, 2001; BURKE, 2003).

In this report, all affected cats were male and had been neutered early, except for P3, who was too young for neutering. The other cats were neutered between 4 and 7 months of age. In P4 the sudden onset of signs after the expected age was probably due to early castration and late closure of physis, predisposing to physeal fracture.

A genetic relationship between these cases cannot be ruled out since owners had no information about the breeding and did not allow specific tests. The findings of this article are in contrast to reports in previous reports with regard to specific breeds being affected since most of the animals in this study were mixed breed, and only one was a Bengal.

All cats were classified as body condition score E by WALTHAN S.H.A.P.E.TM; ie, slightly overweight with fat levels slightly above ideal. Overweight animals may have insulin imbalances, which plays a role by regulating glucose metabolism in chondrocytes and, in large concentrations, insulin can promote differentiation of chondrocytes. Increasing insulin serum concentrations may influence the pathogenesis of the physeal fracture, since abnormal insulin metabolism alters chondrocyte differentiation (DEGÓRKA et al., 2017). Glucose levels were not measured in the patients in this study because none of them appeared hyperglycemic - all patients had access to the street and were able to exercise with no specific clinical signs of altered insulin levels.

On radiographs $\mathrm{P} 1$ had bilateral physeal fractures of the femoral head, with more pronounced muscle atrophy in the right pelvic limb, it is likely that this animal initially had a fracture only on the right side and this went unnoticed by the owner. Subsequently a contralateral fracture developed leading to bilateral lameness which was recognised by the owner (BORAK et al., 2016).
P2 had a fracture in the left femoral neck and displacement of the left femur. P3 had growth plates compatible with age, a fracture in the right femoral neck with alteration in anatomical conformation, more evident on the ventrodorsal projection; and P4 had muscle atrophy of the right limb with a fracture in the femoral head physis.

DEGÓRKA et al., (2017), classifies SCFE by the Salter-Harris classification scheme, which is based on the involvement of the epiphysis, physeal cartilage and metaphysis. Salter Harris type I occurs along the physeal cartilage, type II involves the physeal cartilage and a portion of the metaphysis, type III involves the physeal cartilage and part of the epiphysis, type IV occurs in the epiphysis involving physeal cartilage and metaphysis, type $\mathrm{V}$ are crushing or compressing fractures. There is a type VI characterized by premature closure of a portion of the physeal cartilage, leading to asymmetric closure; however, it is not universally recognized.

Samples from patients with SalterHarris type I fractures showed linear arrangements of chondrocytes on both sides, which differs from epiphysiolysis (CRAIG, 2001; HARASEN, 2004). Findings in SCFE affect both the head and the femoral neck with a wide, irregular and organized area of hypertrophic cartilage, and sometimes the upper femoral epiphysis can be necrotic or can be an intact and viable bone (CRAIG, 2001). In P2, P3 and $\mathrm{P} 4$ the femoral head showed partially preserved bone tissue architecture, small foci of mild trabecular compaction, permeated by reactive fibrovascular tissue and mild bone resorption, and moderate lymphocyte and plasma cell infiltrates were observed in the areas of trabecular fibrosis.

Chondrocytes are typically separated by an abundant matrix and are arranged in irregular, round to polygonal groups, with scarce cytoplasm and minimal cytoplasmic glycogen very similar to mitotic pairs in the reserve zone (SCHWARTZ, 2013). In 
P2, P3 and P4 the chondroid layer was fragmented, irregular, with foci of degeneration and permeated by granulation tissue compatible with reactivity and bone trabecular disorganization with ossification disorder, represented by trabecular fibrosis and immature granulation tissue at the periphery. These findings have also previous been reported.

In some cases, focal hemorrhage and necrosis in the dorsal region of the femoral neck may be filled with proliferating fibroblasts, fibrous connective tissue or granulation tissue at the cleavage site (BORAK et al., 2016). These findings were present in P1 with multifocal areas of necrosis and hemorrhage associated with moderate neovascularization with deposition of fibrous connective tissue and moderately thickened bone trabeculae. These signs are consistent with callus formation and mild inflammation with reactive infiltrates and fibrin exudation. The other cats in this study showed superficial articular cartilage fibrillation with presence of reactive fibrous tissue, neovascularization with tissue permeating the cartilage and an area with fragmented cartilage tissue (Figure 3), indicating early degenerative joint disease and necrotic bone in the epiphyseal medulla, with chondrocyte clusters but with no evidence of collapse.

Some previous reports have employed reconstruction and fixation with multiple pins or $\mathrm{K}$ wires to promote a more rapid recovery and better limb function in the postoperative period (GEMMILL et al. 2012). However, according to FISCHER et al., (2004), internal fixation and anatomical reduction are not necessary to achieve satisfactory clinical results in this disease and there are several factors that can affect the result, such as non-union, avascular necrosis of the head and femoral neck and infection at the surgery site. In some cases it is not possible to reduce the fractures. For these reasons, femoral head and neck osteotomy is the most commonly performed procedure, producing excellent functional results (BORAK et al., 2016).

Despite the lack of reports in the veterinary literature and poor understanding of its etiology, the prognosis for managed cases is excellent. The FHNO allowed fast recovery of the limb in SCFE affected cats, providing good clinical outcomes. Aditionally, it is strongly recommended to follow up the patient due to the increased risk of contralateral joint SCFE, validating the importance of a precise diagnosis.

\section{BIOETHICS AND BIOSSECURITY COMMITTEE APPROVAL}

We authors of the article entitled "Capital femoral physeal dysplasia in cats: a case series" declared, for all due

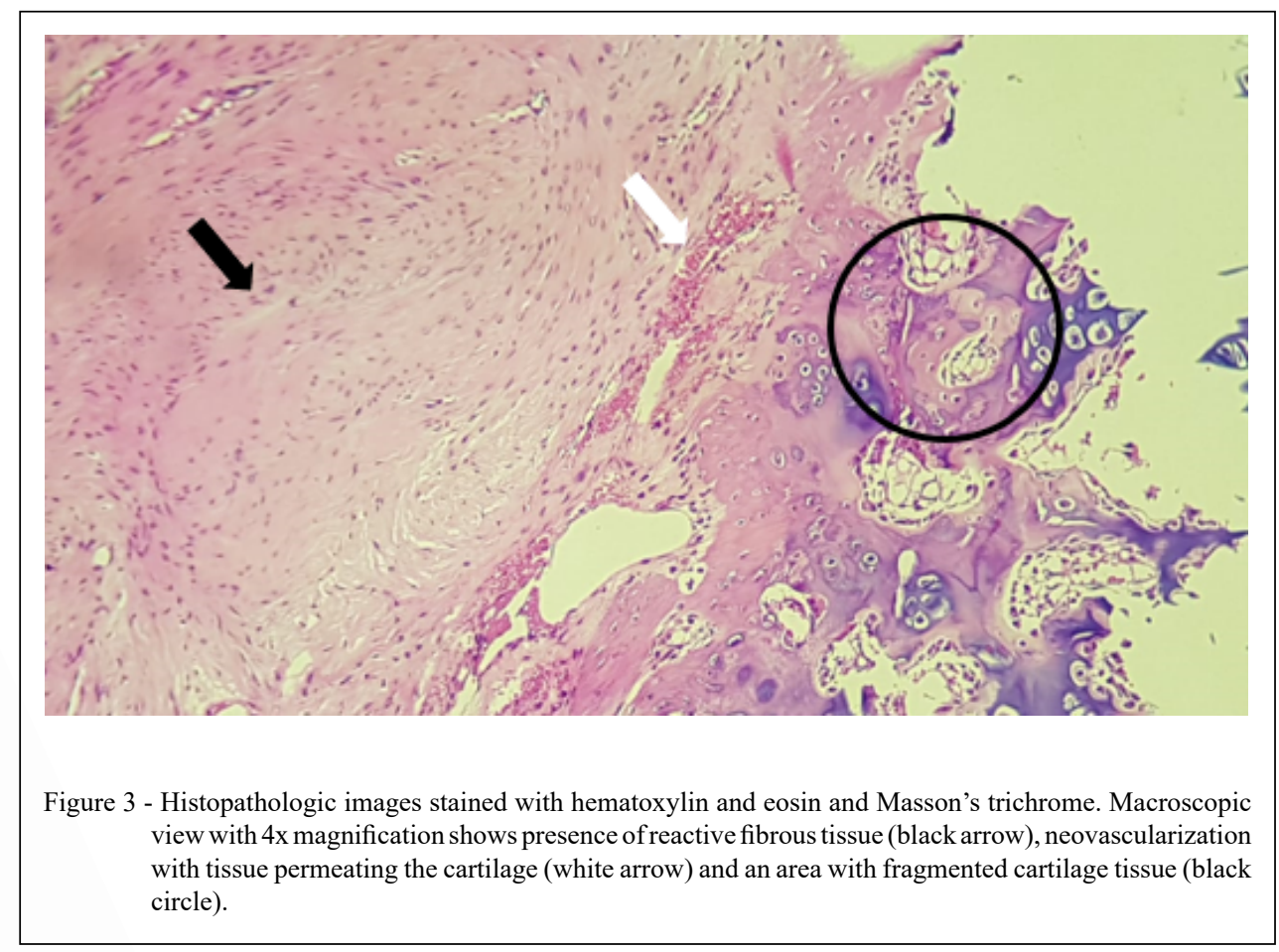

Ciência Rural, v.51, n.7, 2021. 
purposes, the project that gave rise to the present data of the same has not been submitted for evaluation to the Ethics Committee of the University /Research Institute "São Paulo State University (UNESP)", but we are aware of the content of the Brazilian resolutions of the National Council for Control of Animal Experimentation - CONCEA "http://www.mct.gov.br/index.php/ content/view/310553.html" if it involves animals.

Thus, the authors assume full responsibility for the presented data and are available for possible questions, should they be required by the competent authorities.

\section{DECLARATION OF CONFLICT OF INTEREST}

The authors declare no conflict of interest. The founding sponsors had no role in the design of the study; in the collection, analyses, or interpretation of data; in the writing of the manuscript, and in the decision to publish the results.

\section{AUTHORS' CONTRIBUTIONS}

The authors contributed equally to the manuscript.

\section{REFERENCES}

BORAK, D.; et al., Slipped capital femoral epiphysis in 17 Maine Coon cats. Journal of Feline Medicine and Surgery. v.19, n.1, p.13-20, 2016. Available from: <https://doi. org/10.1177/1098612X15598551>. Accessed: Jan. 27, 2019. doi: $10.1177 / 1098612 \times 15598551$.

BURKE, J. Physeal dysplasia with slipped capital femoral epiphysis in a cat. Canadian Veterinary Journal. v.44, p.238239, 2003. Available from: <https://www.ncbi.nlm.nih.gov/pmc/ articles/PMC340087/>. Accessed: Dec. 15, 2019. doi: 10.1093/ med/9780199550647.003.013019.

CRAIG, L. E. Physeal dysplasia with splipped capital femoral ephiphysis in 13 cats. Veterinary Pathology. n.38, n.1, p.92-
97, 2001. Available from: <https://doi.org/10.1354/vp.38-1-92>. Accessed: Nov. 08, 2019. doi: 10.1354/vp.38-1-92.

DEGÓRKA, B., et al., Comparison of usefulness of diferente diagnostic procedures in slipped capital femoral epiphysis in cats. Medycyna Weterynaryjna. v.73, n.10, p.637-641, 2017. Available from: <https:/www.ncbi.nlm.nih.gov/pmc/articles/ PMC2260847/>. Accessed: Nov. 27, 2019. doi: 10.1136/ bmj.2.449.143-a.

FISCHER, H. R.; et al., Surgical reduction and stabilization for repair of femoral capital physeal fractures in cats: 13 cases (1998-2002). Journal of the American Veterinary Medical Association. v.224, n.9, p.1478-1482, 2004. Available from: $<$ https://doi.org/10.2460/javma.2004.224.1478/>. Accessed: Dec. 11, 2019. doi: 10.2460/javma.2004.224.1478.

GEMMILL, T. J., et al., Total hip replacement for the treatment of atraumatic slipped femoral capital epiphysis in dogs. Journal of Small Animal Practice. v.53, n.8, p.453-458, 2012. Available form: <https://doi.org/10.1111 /j.1748-5827.2012.01236.x>. Accessed: Dec. 15, 2019. doi: 10.1111/j.1748-5827.2012.01236.x.

HARASEN, G. Atraumatic proximal femoral physeal fractures in cats. Canadian Veterinary Journal. v.45, p.359360, 2004. Available from: <https://www.ncbi.nlm.nih.gov/ pmc/articles/PMC2751682/>. Acessed: Dec. 20, 2019. doi: PMC2751682.

RAHAL, S. C., et al., Clinical outcome and gait analysis of a cat with bilateral slipped capital femoral epiphysis following bilateral ostectomy of the femoral head and neck. Veterinary Quarterly. v.36, n.2, p.115-119, 2015. Available from: <https://doi.org/10.1 080/01652176.2015.1110642>. Accessed: Nov. 01, 2019. doi: 10.1080/01652176.2015.1110642.

SCHWARTZ, G. Spontaneous capital femoral physeal fracture in a cat. Canadian Veterinary Journal. v.54, n.7, p.698-700, 2013. Available from: <https://www.ncbi.nlm.nih.gov/pmc/articles/ PMC3685007/>. Accessed: Nov. 20, 2019. doi: 24155467. 